\title{
IMPLICIT SELF-STEREOTYPING UNDER EYE GAZE: THE EFFECTS OF GAZE CUES ON IMPLICIT MATH IDENTITY AMONG WOMEN
}

\author{
Yusuke KAROUJI and Takashi KUSUMI
}

Kyoto University, Japan

\begin{abstract}
This paper argues that implicit self-stereotyping is moderated by the potential for social evaluation in that situation. It was hypothesized that implicit self-stereotyping is facilitated when social cues (i.e., gaze cues) signal social evaluation. This study examined whether gaze cues affected implicit self-stereotyping related to gender stereotypes regarding math competence. A pilot study demonstrated that just a presentation of direct-gaze cues (vs. averted-gaze cues) signaled social evaluation and social norms. The main study revealed that gender differences in math identity were more prominent under direct-gaze cues, relative to averted-gaze cues. Women showed more negative math identity than men did when they were exposed to directgaze cues, but not when exposed to averted-gaze cues. Moreover, these effects were particularly prominent among women with stronger implicit math-gender stereotypes and female identity. These findings improve our understanding of how and when implicit self-stereotyping occurs in social situations.
\end{abstract}

Key words: self-stereotyping, implicit self-concept, gender, eye gaze, Implicit Association Test (IAT)

\section{INTRODUCTION}

Pervasive cultural stereotypes are inevitably incorporated into self-concepts, and this process sometimes occurs without conscious awareness (Devos \& Banaji, 2003; Dijksterhuis, Aarts, Bargh, \& van Knippenberg, 2000; Wheeler \& Petty, 2001). Unconscious incorporation of stereotypes into self-concepts is referred to as implicit self-stereotyping (Lun, Sinclair, \& Cogburn, 2009). Especially for stigmatized individuals, the internalization of cultural stereotypes sometimes results in undesirable consequences. For example, implicit math-gender stereotypes predict women's low interest, career orientation, and academic achievement in math (Kiefer \& Sekaquaptewa, 2007; Nosek \& Smyth, 2011; Nosek, et al., 2009). Task performance also suffers as a result of internalized negative stereotypes (i.e., stereotype threat; Aronson, Quinn, \& Spencer, 1998; Schmader, Johns, \& Forbes, 2008; Spencer, Steele, \& Quinn, 1999; Steele \& Aronson, 1995).

We develop stereotype-consistent implicit self-concepts as a function of implicit

We are grateful to Tokika Kurita for collecting the data in the pilot study and for providing valuable comments on earlier versions of this manuscript. This research was supported by a Grant-in-Aid for JSPS fellows (\#09J06736).

Correspondence concerning this article should be addressed to Yusuke Karouji, Graduate School of Education, Kyoto University, Yoshida-Honmachi, Sakyo-ku, Kyoto 606-8501, Japan (e-mail: karouji. yuusuke.2a@kyoto-u.ac.jp). 
stereotypes and group identities (Cadinu \& Galdi, 2012; Cvencek, Meltzoff, \& Greenwald, 2011; Dijksterhuis et al., 2000; Nosek, Banaji, \& Greenwald, 2002). As Nosek et al. (2002) described, a balanced configuration exists among three concepts: the concept of one's ingroup (e.g., female), the concept of the ability domain (e.g., math), and the self-concept. These concepts are intertwined on the principle of consistency. Nosek et al. (2002) demonstrated that stronger implicit math-gender stereotypes (the association of math with male) and implicit gender identity (the association of self with female) corresponded with lower implicit math identity (the association of self with math). As early as elementary school age, children develop an implicit math identity consistent with implicit math-gender stereotypes and gender identity in Western (Cvencek et al., 2011) and Asian cultures (Cvencek, Meltzoff, \& Kapur, 2014). Furthermore, Schmader et al. (2008) argued that stereotype threat stems from a state of imbalance among these links. Therefore, stereotype threat effects are also moderated by the strength of the associative links between stereotypes, group identity, and self-concepts (Forbes \& Schmader, 2010; Gerstenberg, Imhoff, \& Schmitt, 2012; Schmader et al., 2008). For example, the extent of the internalization of math-gender stereotypes moderates women's susceptibility to stereotype threat regarding gender differences in math abilities (Bonnot \& Croizet, 2007; Brown \& Pinel, 2003; Schmader, Johns, \& Barquissau, 2004; Schmader et al., 2008).

According to the framework posed by Nosek et al. (2002), the implicit self-concept is formed in line with cultural stereotypes. However, do stigmatized individuals always engage in implicit self-stereotyping? In the present study, we argue that the level of implicit self-stereotyping is moderated by the potential for social evaluation in that situation. Although cultural stereotypes have chronic effects on self-concepts and self-evaluations, people do not always perceive themselves in line with stereotypes (Crocker, 1999). Crocker (1999) argued that cultural stereotypes are constructed as "shared meanings," and therefore, the effects of stigma are negotiated and created in the situation. The incorporation of cultural stereotypes into self-perceptions of the stigmatized individuals depends on features of the situation that make those cultural stereotypes relevant or irrelevant in that situation. Spencer et al. (1999), for example, demonstrated that gender differences in math performance depend on subtle features of the situation. Gender differences are magnified under stereotype threat of confirming the math-gender stereotype in a diagnostic situation, while gender differences are attenuated or eliminated in a non-diagnostic situation where such threat is reduced. Similarly, gendered behaviors and emotional expressions become prominent under observation or in the presence of others (LaFrance, Hecht, \& Paluck, 2003; Lightdale \& Prentice, 1994). Given that cultural stereotypes are constructed as shared meanings, the applicability of cultural stereotypes to the self depends on whether that situation involves social evaluation. Culturally shared stereotypes are most applicable when social evaluation from others who share the culture is salient in the situation. We can thus assume that self-concepts are sensitive to situational cues related to social evaluation and rapidly regulated in response to those social cues (i.e., implicit self-stereotyping). The greater potential for social evaluation the cues signal in that situation, the more applicable to the self the stereotype becomes. Cultural stereotypes may have the strongest influence in situations involving cues that signal the potential for social evaluation, just as evaluation 
apprehension about confirming the math-gender stereotype in the eyes of others impairs women's performance on mathematical tests. In this study, we directly tested the hypothesis that implicit self-stereotyping would be facilitated in the eyes of others. To investigate the process of unconscious self-stereotyping, we examined self-concepts by using the Implicit Association Test (IAT; Greenwald, McGhee, \& Schwartz, 1998), which is assumed to be less susceptible to social desirability artifacts (Greenwald, Poehlman, Uhlmann, \& Banaji, 2009). Furthermore, we employed subtle nonverbal cues as the stimuli related to social evaluation, which are less likely to invoke participants' intentional responses compared to using verbal instructions. This study examined whether negative self-perceptions related to the math-gender stereotype were activated among women by gaze cues, which are minimal cues that signal social evaluation.

\section{Self-Stereotyping under Eye gaze}

To investigate the effect of social evaluation on implicit self-stereotyping, we employed gaze cues as subtle but important social cues signaling social evaluations (see Frischen, Bayliss, \& Tipper, 2007 for a review). Receiving the direct gaze of others informs us of interests, social evaluations, and social relevance, thereby influencing social perceptions (Adams, Pauker, \& Weisbuch, 2010; Macrae, Hood, Milne, Rowe, \& Mason, 2002; Mason, Tatkow, \& Macrae, 2005) as well as self-cognitions (Wirth, Sacco, Hugenberg, \& Williams, 2010). Even a subtle presentation of eye-like images reminds us of potential observation and affects social judgments and behaviors (Haley \& Fessler, 2005; Powell, Roberts, \& Nettle, 2012). Therefore, our social perceptions are sensitive to whether eye gaze is directed towards or averted from oneself.

Although previous research has demonstrated that the physical presence of others affects implicit attitudes (Boysen, Vogel, \& Madon, 2006; Castelli \& Tomelleri, 2008), respondents may have intentionally, not automatically, regulated their expression of attitudes. To eliminate the effects of self-presentational concerns and examine the effects of subtle situations on implicit self-perceptions, we manipulated gaze direction (direct or averted). We employed eye-image cues, not an actual audience, to focus on the effects of the potential for social evaluation by controlling the effects of any cognitive load or demand characteristics.

We predicted that implicit self-stereotyping would be facilitated under direct-gaze cues compared to averted-gaze cues for several reasons. First, gaze cues heighten the potential for social evaluation, analogous to a diagnostic situation where performance is scrutinized by others and thus likely to invoke stereotype threat among stigmatized individuals (Aronson et al., 1998; Schmader, Forbes, Zhang, \& Mendes, 2009; Steele \& Aronson, 1995). Consequently, such cues may activate negative self-perceptions consistent with stereotypes (Cadinu, Maass, Rosabianca, \& Kiesner, 2005; Gustafsson \& Björklund, 2008; Steele \& Aronson, 1995). Accordingly, direct gaze, compared to averted gaze, would more likely activate negative math identity among women, who are stigmatized and undervalued in math-related fields (Hyde, 2005; Hyde \& Linn, 2006; also in Japan, ElseQuest, Hyde, \& Linn, 2010; Evans, Schweingruber, \& Stevenson, 2002; Nosek et al., 2009; Organisation for Economic Co-operation and Development, 2004). Second, social cues 
signaling observation remind us of social norms and thus facilitate perceptions and behaviors consistent with these social norms (Castelli \& Tomelleri, 2008; Ernest-Jones, Nettle, \& Bateson, 2011; Haley \& Fessler, 2005; LaFrance et al., 2003). Lightdale and Prentice (1994) reported that women showed less aggressive behaviors than men did in individual situations but not in anonymous ones, as social norms discourage women from being aggressive. Such evidence indicates that social cues signaling observation facilitate self-stereotyping consistent with social norms (i.e., gender roles). Given these collective observations, we predicted that direct-gaze cues, compared with averted-gaze cues, would facilitate implicit self-stereotyping according to math-gender stereotypes among women.

\section{The Moderating Roles of Implicit Stereotypes and Group Identity}

We examined the moderating roles of implicit stereotypes and group identity in the influence of eye gaze on implicit self-stereotyping. As previously mentioned, individuals develop implicit self-concepts as a function of implicit stereotypes and group identity (Cadinu \& Galdi, 2012; Cvencek et al., 2011; Cvencek et al., 2014; Dijksterhuis et al., 2000; Nosek et al., 2002). Cvencek and colleagues presented evidence indicating that selfconcepts are developmentally dependent on cultural stereotypes and gender identity (Cvencek et al., 2011; Cvencek et al., 2014). Nosek et al. (2002) demonstrated that stronger implicit math-gender stereotypes $($ math $=$ male) corresponded to lower implicit math identity (math $\neq$ self) for women who implicitly identified with being female rather than male $($ self $=$ female $)$.

Based on the model proposed by Nosek et al. (2002), the current study investigated how implicit gender-math stereotypes and gender identity affected math identity under conditions including gaze cues. We hypothesized that eye gaze would signal social evaluations or social norms and affect the applicability of the stereotype about the social group with which individuals identified. In other words, the effects of eye gaze on implicit self-concepts would depend on the degree of the implicit stereotypes and implicit group identity. Implicit self-stereotyping will be most pronounced in the presence of eye gaze among individuals with the strongest implicit stereotypes and group identity.

\section{The Current Research}

The current research tested the hypothesis that implicit self-stereotyping is facilitated by gaze cues that signal potential social evaluation. Individuals should be more likely to apply ingroup stereotypes to the self under situations in which gaze cues signal potential social evaluation. A pilot study examined whether mere exposure to eye gaze signals social evaluation or social norms. We predicted that direct gaze, relative to averted gaze, would convey the potential for social evaluations and social norms. The primary study examined whether gaze cues (direct vs. averted) triggered implicit self-stereotyping regarding math identity among men and women. Moreover, we addressed how implicit gender-math stereotypes and gender identity affected women's math identity under conditions including gaze cues. We predicted that women would show lower math identity than men would. Furthermore, gender differences in math identity would be greater when individuals are exposed to direct-gaze cues, rather than when they are unobserved (exposed to averted- 
gaze cues). We predicted that these effects would be particularly prominent among women with stronger implicit math-gender stereotypes and female identity.

\section{Pilot Study}

As a first step towards demonstrating implicit self-stereotyping in the eyes of others, we conducted pilot study to confirm that direct gaze cues signal social evaluation and social norms. We examined whether receiving direct eye gaze, relative to averted eye gaze, would make individuals feel socially evaluated or remind them of social norms.

\section{Method}

\section{Gaze cues}

A $189 \times 189$-pixel schematic face depicting gaze cues was presented at the bottom center of a computer screen. A schematic face depicting a direct gaze was presented under the direct-gaze condition, whereas the averted-gaze condition presented a face with its gaze averted downward (see Fig. 1). These stimuli had identical perceptional components with the exception of gaze direction.

\section{Participants, procedure, and dependent measures}

Thirteen female and 15 male Japanese undergraduates completed a series of 12 questions while the face with direct or averted gaze was presented at the bottom of the screen. The order of gaze conditions was counterbalanced across participants. Each item of the dependent measures was presented at the center of the PC screen. First, as a manipulation check, participants indicated the direction in which the eye gaze looked by choosing from five options: forward, up, down, left, or right. All participants correctly recognized the gaze direction in the direct-gaze condition as "forward" and judged the face in the averted-gaze condition as "down." Participants were then asked to report how they felt while the gaze cues were presented on a 7-point Likert scale. Another four items measured how gaze cues aroused feelings of being under social evaluation ("being watched," "being evaluated," "being observed," and "being attended to"; $\alpha=.63$ for the direct-gaze condition and $\alpha=.75$ for the averted-gaze condition). Three items measured the extent to which eye gaze reminded participants of social norms ("being conscious of norms," "being conscious of someone's eyes," and "public"; $\alpha=.41$ for the direct-gaze condition and $\alpha=.70$ for the averted-gaze condition). The questionnaire also contained four items constructed based on the Self-Consciousness Scales (Fenigstein, Scheier, \& Buss, 1975 ) and the Situational Self-Awareness Scale (Govern \& Marsch, 2001) to measure private and public selfawareness ("self-aware," "being conscious of my inner feelings," "being concerned about other's eyes," and "being concerned about what other people think of me"; $\alpha=.72$ for the direct-gaze condition and $\alpha=.81$ for the averted-gaze condition). The order of items, except for the first question about gaze direction, was randomized across participants.

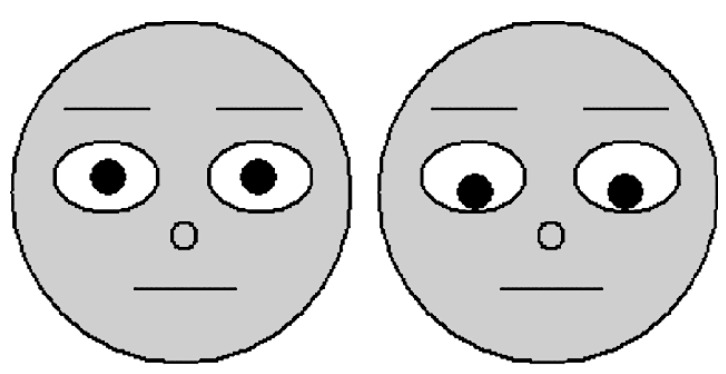

Fig. 1. Schematic faces with direct (left) and averted (right) gazes. 
Table 1. Mean ratings for social evaluation, social norms, and self-awareness (pilot study)

\begin{tabular}{|c|c|c|c|c|c|c|}
\hline \multirow{2}{*}{ Measure } & \multicolumn{2}{|c|}{ Direct } & \multicolumn{2}{|c|}{ Averted } & \multirow{2}{*}{$F(1,26)$} & \multirow{2}{*}{$p$} \\
\hline & $M$ & $S D$ & $M$ & $S D$ & & \\
\hline Social evaluation & 4.66 & 1.09 & 3.22 & 1.28 & 15.11 & $<.001$ \\
\hline Social norms & 4.69 & 1.05 & 3.86 & 1.27 & 11.05 & $<.005$ \\
\hline Self-awareness & 4.64 & 1.14 & 4.88 & 1.25 & 1.19 & .29 \\
\hline
\end{tabular}

Note. Scale ranged from 1 (not at all) to 7 (very much).

\section{Results and Discussion}

We hypothesized that direct-gaze cues, rather than averted-gaze cues, would signal social evaluations and social norms. A 2 (gender) $\times 2$ (gaze) analysis of variance (ANOVA) revealed a significant main effect of gaze on social evaluation, $F(1,26)=15.11, p<.001$, $\eta_{p}{ }^{2}=.37$, and social norms, $F(1,26)=11.05, p<.005, \eta_{p}{ }^{2}=.30$. As predicted, participants felt that they were socially evaluated when faced with direct-gaze cues (see Table 1). Direct-gaze cues also signaled social norms compared to averted-gaze cues. On the other hand, eye gaze did not affect self-awareness, $F(1,26)=1.19, p=.29, \eta_{p}{ }^{2}=.04$, suggesting that receiving direct gaze did not directly affect self-perceptions (explicit self-perceptions, at least) but worked as cues signaling a specific social situation, i.e., a situation under social evaluation and social norms. We found no main effect of gender or interaction effect ( $p \mathrm{~s}>.10$ ), suggesting that the effects of gaze cues were present among both men and women. The results showed that the subtle presentation of eye gaze was sufficient and appropriate for the manipulation of the situation signaling social evaluation and norms.

\section{MAIN STUDY}

The pilot study established that gaze cues signal the potential for social evaluation and social norms. The main study examined whether implicit self-stereotyping related to gender-math stereotypes was facilitated under the presence of gaze cues. Direct gaze, compared to averted gaze, would heighten the applicability of the stereotypes to the self. Furthermore, we examined the relationships among math identity, implicit stereotypes, and gender identity to elucidate the processes underlying implicit self-stereotyping in the presence of gaze cues. Nosek et al. (2002) suggested that self-stereotyping arises as a function of associative links between implicit stereotypes and group identity. We predicted that, under direct-gaze cues, the stronger association between math and male (i.e., implicit stereotypes) and the stronger identification with being female (i.e., implicit gender identity) would correspond with lower identification with mathematics (i.e., implicit math identity). On the other hand, the applicability of the stereotypes to the self would be lower under averted-gaze cues compared to direct-gaze cues. 


\section{Method}

\section{Participants}

Forty-eight female and 48 male Japanese undergraduate and graduate students participated in this experiment in exchange for 500yen (equivalent to US \$5). Participants were randomly assigned to one of two gaze conditions in a 2 (gender: female vs. male) $\times 2$ (gaze: direct vs. averted) factorial design.

\section{Gaze cues}

The same schematic face used in the pilot study was presented at the bottom center of a computer screen. The schematic face depicting a direct gaze was presented in the direct-gaze condition, and the face with its gaze averted downward was presented in the averted-gaze condition.

\section{Measures}

Three IATs were conducted to assess implicit math identity (i.e., the association between the self and math vs. other and math), implicit math-gender stereotypes (i.e., the association between math and male vs. math and female), and implicit gender identity (i.e., the association between the self and female vs. self and male).

IATs were administered and scored according to standard procedures (Greenwald, Nosek, \& Banaji, 2003). These consisted of seven blocks in which participants categorized word stimuli into left- or rightassigned categories as quickly and precisely as possible by using two keys ("F" and "J") on a computer keyboard. In the math identity IAT, for example, participants categorized stimuli representing concepts of math (e.g., "calculation" and "equation") and language (e.g., "grammar" and "syntax") and attributes of the self (e.g., "I" and "my") and other (e.g., "others" and "other's"). The IAT has two critical blocks; in the congruent block, the stimuli representing math and the self are mapped to one key and those representing language and other to another key, while in the incongruent block, stimuli representing language and the self are mapped to one key and math and other to another key. If a participant identified strongly with math, then the reaction times in the congruent block would be faster than those in the incongruent block. Each critical block consisted of 60 trials in total. All stimuli were presented in Japanese. Response latencies were recorded from the beginning of the trial to the time participants offered a correct response.

The IAT $D$-scores were calculated following the scoring procedure recommended by Greenwald et al. (2003). Implicit math identity was calculated by subtracting the average reaction time in the "self + math" block (in which self was paired with math) from that in the "self + language" block on the math identity IAT. Positive scores indicate greater implicit math identity (association between self and math), whereas negative scores indicate greater implicit language identity. Likewise, implicit math-gender stereotype IAT scores were calculated by subtracting the average reaction time in the "math + male" block from that in the "math + female" block, while implicit gender identity IAT scores were calculated by subtracting the average reaction time in the "self + female" block from that in the "self + male" block. Positive scores on the math-gender stereotype IAT and the gender identity IAT indicate greater implicit math-gender stereotypes and implicit female identity, respectively.

\section{Procedure}

After receiving brief instructions from a male experimenter, participants individually completed three IATs. The order of the three IATs was counterbalanced by a Latin-square design. The face depicting either the direct or the averted gaze was presented at the bottom of the screen while participants completed the IATs. Participants wore noise-cancelling headphones during the experiment to enhance privacy. After all of the IATs, participants were screened for awareness of the hypothesis related to gaze cues. Because no one was aware of the connection between the IATs and gaze cues, all of participants were included in the analyses.

\section{Results and Discussion}

\section{The effects of eye gaze}

A 2 (gender) $\times 2$ (gaze) ANOVA revealed a marginally significant effect of gender on implicit math identity, $F(1,92)=3.52, p<.10, \eta_{p}{ }^{2}=.04$. Female participants $(M=-0.28)$ 


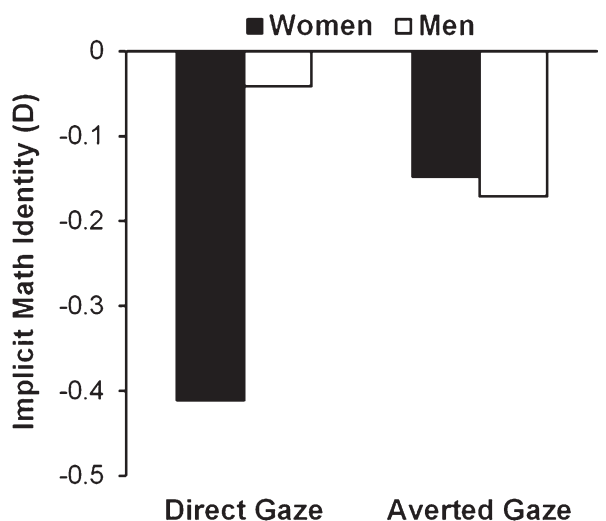

Fig. 2. Implicit math identity as a function of gender and gaze. Negative values indicate weaker math identity relative to language identity.

showed weaker math identity than did male participants $(M=-0.11)$. As expected, a significant interaction between gaze and gender emerged, $F(1,92)=4.51, p<.05, \eta_{p}{ }^{2}=.05$. Female participants showed lower math identity $(M=-0.41)$ than did male participants $(M=-0.04)$ under the direct-gaze condition, but no significant differences in math identity were observed between women $(M=-0.15)$ and men $(M=-0.17)$ under the averted-gaze condition (Fig. 2). These results support the hypothesis that implicit self-stereotyping can be facilitated by a gaze that signals social evaluation, that is, implicit self-stereotyping in the eyes of others.

We also conducted a 2 (gender) $\times 2$ (gaze) ANOVA on implicit math-gender stereotype and implicit gender identity. We found no differences between conditions, except for a significant effect of gender on implicit gender identity $F(1,92)=84.88, p<.001, \eta_{p}{ }^{2}=.48$, suggesting that women $(M=0.49)$ had stronger implicit identification with being female than did men $(M=-0.33)$. Effects of gaze were found for only implicit math identity. As shown in the pilot study, these results suggest that gaze cues did not affect self-perception as a whole (i.e., both gender identity and math identity), but specifically affected the applicability of the stereotypes to the self.

\section{Moderating roles of implicit stereotypes and gender identity}

We conducted multiple regression analyses to predict math identity by separately examining implicit stereotypes, participant gender (coded -1 for men, 1 for women), and the interaction between stereotypes and participant gender under the direct- and avertedgaze conditions (Model 1). As shown in Table 2, implicit stereotypes $(\beta=-.30, p<.05)$ and participant gender $(\beta=-.33, p<.05)$ were negatively correlated with implicit math identity under the direct-gaze condition, but not under the averted-gaze condition (stereotypes $\beta=.05$, n.s.; gender identity $\beta=.03$, n.s.). Moreover, as predicted, a stereotype $\times$ participant gender interaction corresponded to negative math identity under the direct-gaze condition $(\beta=-.41, p<.01)$, but not under the averted-gaze condition 

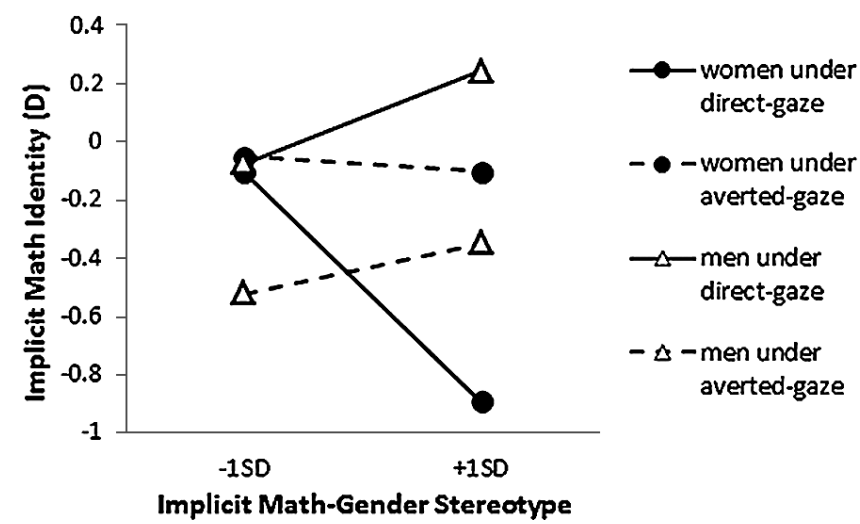

Fig. 3. Implicit math identity as a function of implicit stereotypes, gender and gaze.

Table 2. Beta weights from the regression analysis predicting implicit math identity

\begin{tabular}{lccccc}
\hline \multirow{2}{*}{ Variable } & \multicolumn{2}{c}{ Model 1 } & & \multicolumn{2}{c}{ Model 2 } \\
\cline { 2 - 3 } \cline { 5 - 6 } & Direct & Averted & & Direct & Averted \\
\hline Stereotype & $-.30^{*}$ & .05 & & $-.24^{\dagger}$ & .09 \\
Participant gender & $-.33^{*}$ & .03 & & & \\
Stereotype $\times$ Participant gender & $-.41^{* *}$ & -.03 & & & \\
Gender identity & & & & $-.34^{*}$ & -.17 \\
Stereotype $\times$ Gender identity & & & & $-.38^{* *}$ & -.20 \\
\hline \multicolumn{1}{c}{$R^{2}$} & $.33^{* *}$ & .00 & & $.29^{* *}$ & .06 \\
\hline
\end{tabular}

Note. ${ }^{\dagger} p<.10,{ }^{*} p<.05, * * p<.01$

$(\beta=-.03, n . s$.$) . This significant interaction indicated that stronger math-gender stereotypes$ were associated with more negative math identity for women $(\beta=-.68, p<.01)$, but not for men $(\beta=.13, n . s$.$) , under the direct-gaze condition. Fig. 3$ shows the pattern of implicit math identity as a function of implicit math-gender stereotypes $( \pm 1 S D)$ and participant gender under the direct and averted gaze conditions. These results suggest that implicit self-concepts are attuned to implicit stereotypes associated with one's own group in response to gaze cues.

We also conducted multiple regression analyses to predict math identity by entering implicit stereotypes, gender identity, and the interaction between stereotypes and gender identity into the model (Model 2). The model proposed by the previous analysis (Model 1) was replicated by including gender identity instead of participant gender as a predictor in the model. Consistent with Model 1, female-identified participants with stronger mathgender stereotypes showed weaker math identity under direct-gaze cues (Table 2). 
The model presented by Nosek et al. (2002) was replicated under the direct-gaze condition, but not under the averted-gaze condition. Nosek et al. (2002) demonstrated that implicit stereotypes and gender identity shaped gender differences in attitudes and identity with mathematics. We further found that these relationships were moderated by situational cues. They were especially applicable in the presence of cues signaling social evaluation and social norms, whereas they were less applicable in situations including few social cues.

\section{GENERAL DisCUSSION}

The current study supported the hypothesis that implicit self-stereotyping can be moderated by gaze cues signaling social evaluations. The results showed that the applicability of stereotypes to the self was adjusted in response to eye gaze. Gender differences in implicit math identity were minimal when individuals were not targeted by gaze cues. In contrast, women showed more stereotype-consistent negative math identity than did men when they were targeted by gaze cues. These results suggest that implicit self-concepts can be regulated in response to subtle social cues; implicit self-stereotyping is facilitated in response to eye gaze. As shown in the pilot study, eye gaze enhances the potential for social evaluation, which can induce evaluative apprehension for being a target of stereotyping. Eye gaze also signals the social norm that individuals should conform to gender roles. As a result, implicit self-stereotyping is facilitated when social cues are salient compared to when social evaluations and norms are less salient.

A multiple regression analysis further showed that implicit self-concepts were adjusted such that they correspond with implicit stereotypes and group identity. Women who internalize stereotypes and gender identity are most susceptible to gaze cues, implicitly self-stereotyping with ingroup stereotypes under direct-gaze cues. These results are consistent with past research that showed that women (low-status group) are more likely to engage in self-stereotyping than men (high-status group) are (Cadinu \& Galdi, 2012; Latrofa, Vaes, Cadinu, \& Carnaghi, 2010). The current research adds a new finding that stigmatized individuals do not always perceive themselves according to internalized stereotypes. Their self-perception depends on whether social cues are salient in a given situation. Gaze cues might affect the applicability of stereotypes to the self and produce subsequent changes in self-perceptions. DeMarree and Loersch (2009) showed that exposure to a prime can produce prime-consistent changes in self-perceptions only when the self is relevant. Direct-gaze cues might remind one of the potential that the self is a target of social evaluation and increase the applicability of implicit stereotypes. Alternatively, averted-gaze cues might signal that he or she is not a target of social evaluation in that situation. Zhang, Schmader, and Hall (2013) reported that disassociating the self from an evaluative situation, achieved by asking participants to use a fictitious name (rather than a real name) in a math test, decreased self-evaluative concerns among women and alleviated negative effects of stereotype threat on math performance. Avertedgaze cues might signal a less evaluative situation, therefore reducing the applicability of implicit stereotypes to the self. 
The present research increases our understanding of how and when self-stereotyping occurs in social situations. We employed a subtle cue and manipulated gaze direction (i.e., being watched or not) rather than comparing situations that do or do not include others. We demonstrated, through minimal manipulation, that the potential for social evaluation moderated implicit self-stereotyping, extending previous findings and further indicating that self-stereotyping can unconsciously occur in response to social cues signaling social evaluation and social norms. This suggests the possibility that unwanted self-stereotyping with culturally shared expectations can be induced among stigmatized individuals in social situations where they are targets of social evaluation.

Although we employed an abstract picture of eye gaze to examine the subtle effects of eye gaze and minimize the influence of demand characteristics, the effects observed in the present study might be magnified by using gaze from a real person or a photograph of a face. The effects of gaze are predicted to depend on the source of the eye gaze (e.g., a significant other, an ingroup member, or an outgroup member). Previous studies demonstrated that the presence of men in a testing environment works as a threatening cue for women and impairs women's performance (Inzlicht \& Ben-Zeev, 2000). Furthermore, negative effects of stereotype threat are more prominent when an outgroup member administers the test but are weaker when an ingroup member administers the test (Marx \& Goff, 2005). Employing a photograph of a face as a social cue in future research will improve our understanding of the mechanism of implicit self-stereotyping. Future work should also address the effects of gaze cues in detail in order to reveal the mechanism by which gaze cues influence implicit self-concepts. The pilot study showed that individuals perceive gaze cues as signals for social evaluations and social norms, but we did not directly examine whether gaze cues activated social evaluations and social norms without participants' conscious awareness. Future research should examine the effects of gaze cues on the unconscious process.

Perhaps most importantly, the effects of gaze cues were pronounced among stigmatized individuals in math-related domains, i.e., women. This result is consistent with stereotype threat effects. As a consequence of continuous exposure to evaluations based on negative stereotypes, stigmatized individuals internalize negative stereotypes (Bonnot \& Croizet, 2007; Cioffi, 2000) and automatically attend to threatening cues (Kaiser, Vick, \& Major, 2006), which might explain why women's self-concepts were more sensitive to gaze cues and more strongly influenced by these stimuli than were those of men. These findings offer several important implications related to stereotype threat. Stereotype threat is defined as evaluation apprehension that one could confirm a negative stereotype in the "eyes" of others or of oneself (Aronson et al., 1998). This study demonstrates that literal eyes can induce negative self-perceptions that are consistent with stereotypes. Future research should investigate whether gaze cues affect actual performance on math-related tasks as well as self-cognitions regarding math.

Future research should also examine whether the same findings are generalizable to other groups connected with other stereotypes. The current research focused on implicit self-stereotyping with math-gender stereotypes. Math-gender stereotypes are related to academic achievements and competence, which are strongly associated with social 
evaluation and testing situations. Previous studies have shown that diagnosticity and evaluation have a key role in stereotype threat effects (e.g., Jamieson \& Harkins, 2010). Therefore, implicit math identity may be particularly susceptible to gaze cues that signal social evaluation. Although we did not hypothesize that the effects of social cues on implicit self-stereotyping are limited to specific groups, some social cues have different effects on specific groups depending on stereotype contents.

In addition, the method for measuring implicit self-concepts must be improved in future research. Because an IAT fundamentally requires complementary pairs of categories, the implicit math identity in this study was measured as the association between the self and math in comparison to language. Therefore, we could not determine whether implicit self-stereotyping occurred because of decreased math identity or because of increased language identity, although gaze cues facilitated implicit self-stereotyping among women. Adoption of the priming procedure or the single-category IAT (Karpinski \& Steinman, 2006) in future work will help shed light on the process of implicit self-stereotyping.

In conclusion, this study provided direct evidence for the first time that implicit selfconcepts can be socially attuned in a stereotype-consistent manner by nonverbal cues signaling social evaluation; that is, implicit self-stereotyping is facilitated in the presence of eye gaze. At the same time, the results indicate the harmful effects of being chronically evaluated as the target of stereotyping. As a consequence of internalizing cultural stereotypes, stigmatized individuals may implicitly perceive themselves as fitting those stereotypes and thus behave in a stereotype-consistent manner-sometimes in an undesirable manner-when the potential for social evaluation is salient. Further research on implicit self-stereotyping will offer new insights into how stigmatized individuals perceive themselves in social situations.

\section{REFERENCES}

Adams, R. B., Jr., Pauker, K., \& Weisbuch, M. 2010. Looking the other way: The role of gaze direction in the cross-race memory effect. Journal of Experimental Social Psychology, 46, 478-481.

Aronson, J., Quinn, D. M., \& Spencer, S. J. 1998. Stereotype threat and the academic underperformance of minorities and women. In J. K. Swim \& C. Stangor (Eds.), Prejudice: The target's perspective (pp. 83-103). San Diego, CA: Academic Press.

Bonnot, V., \& Croizet, J. C. 2007. Stereotype internalization and women's math performance: The role of interference in working memory. Journal of Experimental Social Psychology, 43, 857-866.

Boysen, G. A., Vogel, D. L., \& Madon, S. 2006. A public versus private administration of the implicit association test. European Journal of Social Psychology, 36, 845-856.

Brown, R. P., \& Pinel, E. C. 2003. Stigma on my mind: Individual differences in the experience of stereotype threat. Journal of Experimental Social Psychology, 39, 626-633.

Cadinu, M., \& Galdi, S. 2012. Gender differences in implicit gender self-categorization lead to stronger gender self-stereotyping by women than by men. European Journal of Social Psychology, 42, 546551.

Cadinu, M., Maass, A., Rosabianca, A., \& Kiesner, J. 2005. Why do women underperform under stereotype threat? Evidence for the role of negative thinking. Psychological Science, 16, 572-578.

Castelli, L., \& Tomelleri, S. 2008. Contextual effects on prejudiced attitudes: When the presence of others leads to more egalitarian responses. Journal of Experimental Social Psychology, 44, 679-686.

Cioffi, D. 2000. The looking-glass self revisited: Behavior choice and self-perception in the social token. In 
T. F. Heatherton, R. E. Kleck, M. R. Hebl, \& J. G. Hull (Eds.), The social psychology of stigma (pp. 184-219). New York, NY: The Guilford Press.

Crocker, J. 1999. Social stigma and self-esteem: Situational construction of self-worth. Journal of Experimental Social Psychology, 35, 89-107.

Cvencek, D., Meltzoff, A. N., \& Greenwald, A. G. 2011. Math-gender stereotypes in elementary school children. Child Development, 82, 766-779.

Cvencek, D., Meltzoff, A. N., \& Kapur, M. 2014. Cognitive consistency and math-gender stereotypes in Singaporean children. Journal of Experimental Child Psychology, 117, 73-91.

DeMarree, K. G., \& Loersch, C. 2009. Who am I and who are you? Priming and the influence of self versus other focused attention. Journal of Experimental Social Psychology, 45, 440-443.

Devos, T., \& Banaji, M. R. 2003. Implicit self and identity. In M. R. Leary \& J. P. Tangney (Eds.), Handbook of self and identity (pp. 153-175). New York, NY: The Guilford Press.

Dijksterhuis, A., Aarts, H., Bargh, J. A., \& van Knippenberg, A. 2000. On the relation between associative strength and automatic behavior. Journal of Experimental Social Psychology, 36, 531-544.

Else-Quest, N. M., Hyde, J. S., \& Linn, M. C. 2010. Cross-national patterns of gender differences in mathematics: A meta-analysis. Psychological Bulletin, 136, 103-127.

Ernest-Jones, M., Nettle, D., \& Bateson, M. 2011. Effects of eye images on everyday cooperative behavior: A field experiment. Evolution and Human Behavior, 32, 172-178.

Evans, E. M., Schweingruber, H., \& Stevenson, H. W. 2002. Gender differences in interest and knowledge acquisition: The United States, Taiwan, and Japan. Sex Roles, 47, 153-167.

Fenigstein, A., Scheier, M. F., \& Buss, A. H. 1975. Public and private self-consciousness: Assessment and theory. Journal of Consulting and Clinical Psychology, 43, 522-527.

Forbes, C. E., \& Schmader, T. 2010. Retraining attitudes and stereotypes to affect motivation and cognitive capacity under stereotype threat. Journal of Personality and Social Psychology, 99, 740-754.

Frischen, A., Bayliss, A. P., \& Tipper, S. P. 2007. Gaze cueing of attention: Visual attention, social cognition, and individual differences. Psychological Bulletin, 133, 694-724.

Gerstenberg, F. X. R., Imhoff, R., \& Schmitt, M. 2012. 'Women are bad at math, but I'm not, am I?' Fragile mathematical self-concept predicts vulnerability to a stereotype threat effect on mathematical performance. European Journal of Personality, 26, 588-599.

Govern, J. M., \& Marsch, L. A. 2001. Development and validation of the situational self-awareness scale. Consciousness and Cognition, 10, 366-378.

Greenwald, A. G., McGhee, D. E., \& Schwartz, J. L. K. 1998. Measuring individual differences in implicit cognition: The implicit association test. Journal of Personality and Social Psychology, 74, 1464-1480.

Greenwald, A. G., Nosek, B. A., \& Banaji, M. R. 2003. Understanding and using the Implicit Association Test: I. An improved scoring algorithm. Journal of Personality and Social Psychology, 85, 197-216.

Greenwald, A. G., Poehlman, T. A., Uhlmann, E. L., \& Banaji, M. R. 2009. Understanding and using the Implicit Association Test: III. Meta-analysis of predictive validity. Journal of Personality and Social Psychology, 97, 17-41.

Gustafsson, U., \& Björklund, F. 2008. Women self-stereotype with feminine stereotypical traits under stereotype threat. Current Research in Social Psychology, 13, 219-231.

Haley, K. J., \& Fessler, D. M. T. 2005. Nobody's watching?: Subtle cues affect generosity in an anonymous economic game. Evolution and Human Behavior, 26, 245-256.

Hyde, J. S. 2005. The gender similarities hypothesis. American Psychologist, 60, 581-592.

Hyde, J. S., \& Linn, M. C. 2006. Gender similarities in mathematics and science. Science, 314, 599-600.

Inzlicht, M., \& Ben-Zeev, T. 2000. A threatening intellectual environment: Why females are susceptible to experiencing problem-solving deficits in the presence of males. Psychological Science, 11, 365-371.

Jamieson, J. P., \& Harkins, S. G. 2010. Evaluation is necessary to produce stereotype threat performance effects. Social Influence, 5, 75-86.

Kaiser, C. R., Vick, S. B., \& Major, B. 2006. Prejudice expectations moderate preconscious attention to cues that are threatening to social identity. Psychological Science, 17, 332-338.

Karpinski, A., \& Steinman, R. B. 2006. The Single Category Implicit Association Test as a measure of implicit social cognition. Journal of Personality and Social Psychology, 91, 16-32.

Kiefer, A. K., \& Sekaquaptewa, D. 2007. Implicit stereotypes, gender identification, and math-related outcomes: A prospective study of female college students. Psychological Science, 18, 13-18. 
LaFrance, M., Hecht, M. A., \& Paluck, E. L. 2003. The contingent smile: A meta-analysis of sex differences in smiling. Psychological Bulletin, 129, 305-334.

Latrofa, M., Vaes, J., Cadinu, M., \& Carnaghi, A. 2010. The cognitive representation of self-stereotyping. Personality and Social Psychology Bulletin, 36, 911-922.

Lightdale, J. R., \& Prentice, D. A. 1994. Rethinking sex differences in aggression: Aggressive behavior in the absence of social roles. Personality and Social Psychology Bulletin, 20, 34-44.

Lun, J., Sinclair, S., \& Cogburn, C. 2009. Cultural stereotypes and the self: A closer examination of implicit self-stereotyping. Basic and Applied Social Psychology, 31, 117-127.

Macrae, C. N., Hood, B., Milne, A. B., Rowe, A. C., \& Mason, M. F. 2002. Are you looking at me? Eye gaze and person perception. Psychological Science, 13, 460-464.

Marx, D. M., \& Goff, P. A. 2005. Clearing the air: The effect of experimenter race on target's test performance and subjective experience. British Journal of Social Psychology, 44, 645-657.

Mason, M. F., Tatkow, E. P., \& Macrae, C. N. 2005. The look of love: Gaze shifts and person perception. Psychological Science, 16, 236-239.

Nosek, B. A., Banaji, M. R., \& Greenwald, A. G. 2002. Math $=$ male, me $=$ female, therefore math $\neq$ me. Journal of Personality and Social Psychology, 83, 44-59.

Nosek, B. A., \& Smyth, F. L. 2011. Implicit social cognitions predict sex differences in math engagement and achievement. American Educational Research Journal, 48, 1125-1156.

Nosek, B. A., Smyth, F. L., Sriram, N., Lindner, N. M., Devos, T., Ayala, A., ... Greenwald, A. G. 2009. National differences in gender-science stereotypes predict national sex differences in science and math achievement. Proceedings of the National Academy of Sciences, 106, 10593-10597.

Organisation for Economic Co-operation and Development. 2004. Learning for tomorrow's world: First results from PISA 2003. Paris: Author.

Powell, K. L., Roberts, G., \& Nettle, D. 2012. Eye images increase charitable donations: Evidence from an opportunistic field experiment in a supermarket. Ethology, 118, 1096-1101.

Schmader, T., Forbes, C. E., Zhang, S., \& Mendes, W. B. 2009. A metacognitive perspective on the cognitive deficits experienced in intellectually threatening environments. Personality and Social Psychology Bulletin, 35, 584-596.

Schmader, T., Johns, M., \& Barquissau, M. 2004. The costs of accepting gender differences: The role of stereotype endorsement in women's experience in the math domain. Sex Roles, 50, 835-850.

Schmader, T., Johns, M., \& Forbes, C. 2008. An integrated process model of stereotype threat effects on performance. Psychological Review, 115, 336-356.

Spencer, S. J., Steele, C. M., \& Quinn, D. M. 1999. Stereotype threat and women's math performance. Journal of Experimental Social Psychology, 35, 4-28.

Steele, C. M., \& Aronson, J. 1995. Stereotype threat and the intellectual test performance of African Americans. Journal of Personality and Social Psychology, 69, 797-811.

Wheeler, S. C., \& Petty, R. E. 2001. The effects of stereotype activation on behavior: A review of possible mechanisms. Psychological Bulletin, 127, 797-826.

Wirth, J. H., Sacco, D. F., Hugenberg, K., \& Williams, K. D. 2010. Eye gaze as relational evaluation: Averted eye gaze leads to feelings of ostracism and relational devaluation. Personality and Social Psychology Bulletin, 36, 869-882.

Zhang, S., Schmader, T., \& Hall, W. M. 2013. L'eggo my ego: Reducing the gender gap in math by unlinking the self from performance. Self and Identity, 12, 400-412. 